\title{
A Study of Nighttime Seat Belt Use in INDIANA
}

\author{
JONATHON M. VIVODA \\ DAVID W. EBY \\ RENÉE M. ST. LOUIS \\ LIDIA P. KOSTYNIUK
}




\title{
A Study of Nighttime Seat Belt Use in Indiana
}

\author{
Jonathon M. Vivoda \\ David W. Eby \\ Renée M. St. Louis \\ Lidia P. Kostyniuk
}

The University of Michigan

Transportation Research Institute

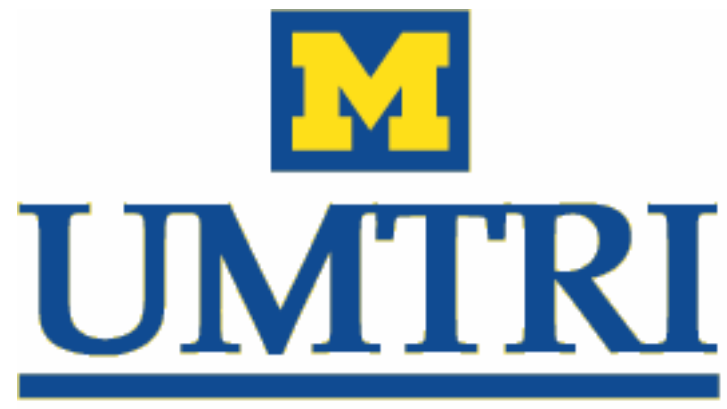


Technical Report Documentation Page

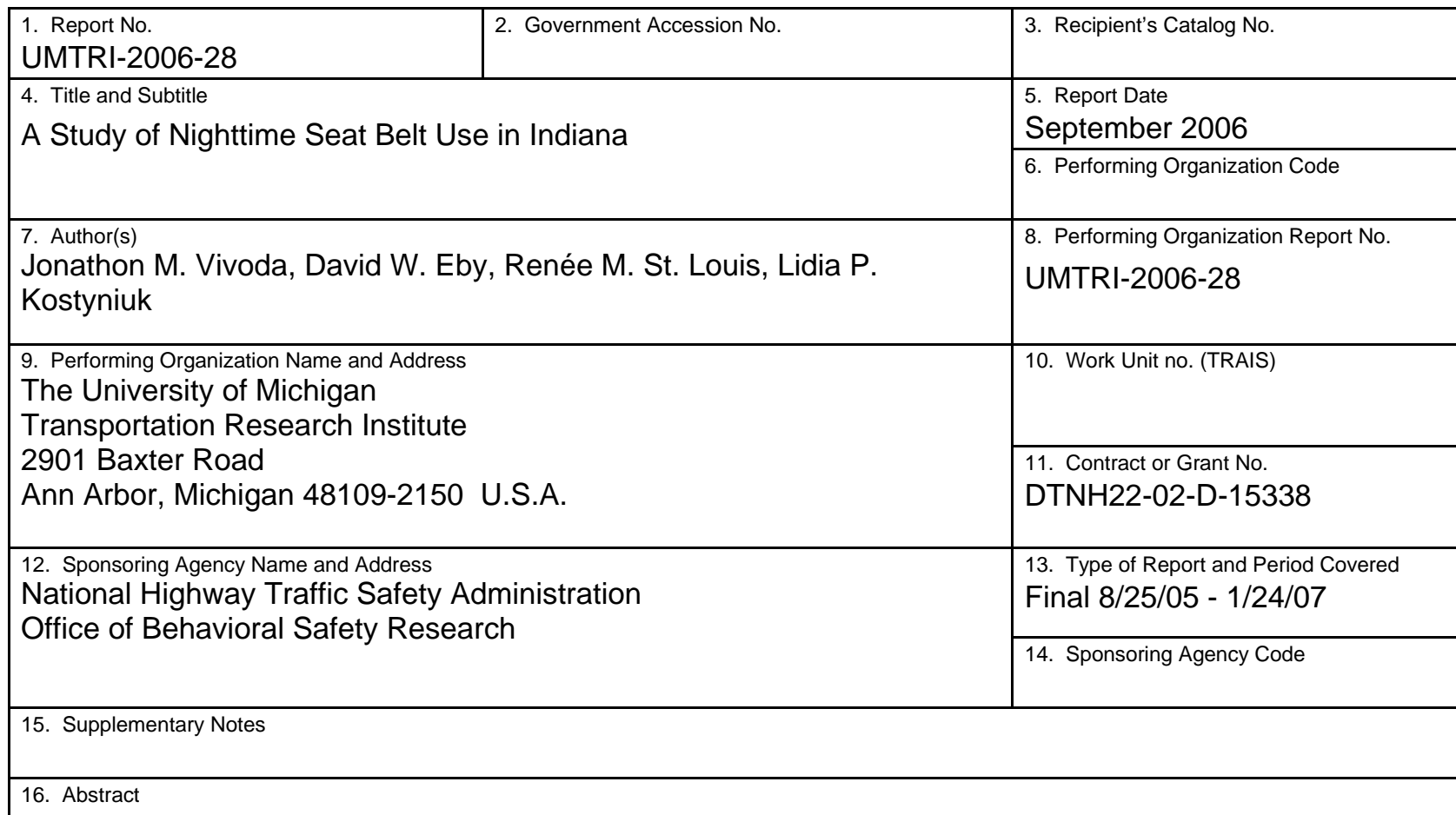

A direct observation study of nighttime seat belt use was conducted in Indiana surrounding the Click It or Ticket (May Mobilization) activities. Two nighttime full statewide surveys were conducted, one in April and the other in June 2006. For this study, the hours between 9:30 p.m. to 5:45 a.m. were defined as nighttime. This time included all hours of darkness between the end of twilight in the evening to the beginning of twilight in the morning during June 2006 in Indianapolis, Indiana. Observations were conducted at roadway intersections, freeway entrance and exit ramps, and road segments using specialized night vision equipment. The nighttime survey waves were designed to coincide with daytime waves already planned for Indiana by the Center for the Advancement of Transportation Safety, and the Indiana Criminal Justice Institute. The first objective of the study was to determine if there was a differential change in daytime versus nighttime seat belt use surrounding the mobilization activities. A secondary objective was to compare daytime to nighttime seat belt use to see if there was lower seat belt use at night, as has been found by others.

The comparisons across the mobilization period revealed a statistically significant increase during the day $(79.7 \%$ and $84.3 \%$, respectively), and a statistically significant decrease at night $(79.0 \%$ and $74.0 \%$, respectively). These results suggest that the daytime mobilization activities had a positive effect on daytime belt use, but no effect on nighttime belt use. There is no obvious reason for the belt use decrease observed at night during this period.

Comparisons were also made between daytime and nighttime belt use within each time period (pre- and post-mobilization). No differences were observed during the pre-mobilization wave, while a statistically significant difference was observed during the post wave. This difference is jointly attributed to the differential effect of the mobilization activities on daytime and nighttime belt use across the mobilization period, and the decrease observed within the nighttime waves.

Finally, many of the common daytime trends in belt use (i.e., lower belt use for males than females) were also found at night, with the exception of the effect of age (typically younger motorists buckle up less often) and seating position (typically drivers display higher belt use).

\begin{tabular}{|c|c|c|c|}
\hline \multicolumn{2}{|c|}{$\begin{array}{l}\text { 17. Key Words } \\
\text { Safety belt use, seat belt use, nighttime, direct observation, mobilization, } \\
\text { occupant protection }\end{array}$} & \multicolumn{2}{|c|}{$\begin{array}{l}\text { 18. Distribution Statement } \\
\text { Unlimited }\end{array}$} \\
\hline $\begin{array}{l}\text { 19. Security Classification (of this report) } \\
\text { Unclassified }\end{array}$ & $\begin{array}{l}\text { 20. Security Classification (of this page) } \\
\text { Unclassified }\end{array}$ & $\begin{array}{l}\text { 21. No. of Pages } \\
27\end{array}$ & 22. Price \\
\hline
\end{tabular}




\section{SI* (MODERN METRIC) CONVERSION FACTORS}

APPROXIMATE CONVERSIONS TO SI UNITS

\begin{tabular}{|c|c|c|c|c|}
\hline Symbol & When You Know & Multiply By & To Find & Symbol \\
\hline \multicolumn{5}{|c|}{ LENGTH } \\
\hline in & inches & 25.4 & millimeters & $\mathrm{mm}$ \\
\hline $\mathrm{ft}$ & feet & 0.305 & meters & $\mathrm{m}$ \\
\hline yd & yards & 0.914 & meters & $\mathrm{m}$ \\
\hline $\mathrm{mi}$ & miles & 1.61 & kilometers & $\mathrm{km}$ \\
\hline \multicolumn{5}{|c|}{ AREA } \\
\hline in $^{2}$ & square inches & 645.2 & square millimeters & $\mathrm{mm}^{2}$ \\
\hline $\mathrm{ft}^{2}$ & square feet & 0.093 & square meters & $\mathrm{m}_{2}^{2}$ \\
\hline $\mathrm{yd}^{2}$ & square yard & 0.836 & square meters & $\mathrm{m}^{2}$ \\
\hline $\mathrm{ac}$ & acres & 0.405 & hectares & ha \\
\hline $\mathrm{mi}^{2}$ & square miles & 2.59 & square kilometers & $\mathrm{km}^{2}$ \\
\hline \multicolumn{5}{|c|}{ VOLUME } \\
\hline $\mathrm{fl} \mathrm{oz}$ & fluid ounces & 29.57 & milliliters & $\mathrm{mL}$ \\
\hline gal & gallons & 3.785 & liters & $\mathrm{L}_{3}$ \\
\hline $\mathrm{ft}^{3}$ & cubic feet & 0.028 & cubic meters & $\mathrm{m}^{3}$ \\
\hline $\mathrm{yd}^{3}$ & cubic yards & 0.765 & cubic meters & $\mathrm{m}^{3}$ \\
\hline \multicolumn{5}{|c|}{ NOTE: volumes greater than $1000 \mathrm{~L}$ shall be shown in $\mathrm{m}^{3}$} \\
\hline & & MASS & & \\
\hline $\mathrm{oz}$ & ounces & 28.35 & grams & g \\
\hline $\mathrm{lb}$ & pounds & 0.454 & kilograms & \\
\hline $\mathrm{T}$ & short tons (2000 lb) & 0.907 & megagrams (or "metric ton") & Mg (or "t") \\
\hline \multicolumn{5}{|c|}{ TEMPERATURE (exact degrees) } \\
\hline${ }^{\circ} \mathrm{F}$ & Fahrenheit & $\begin{array}{l}5(\mathrm{~F}-32) / 9 \\
\text { or }(\mathrm{F}-32) / 1\end{array}$ & Celsius & ${ }^{\circ} \mathrm{C}$ \\
\hline \multicolumn{5}{|c|}{ ILLUMINATION } \\
\hline fc & foot-candles & 10.76 & & \\
\hline $\mathrm{fl}$ & foot-Lamberts & 3.426 & candela $/ \mathrm{m}^{2}$ & $\mathrm{~cd} / \mathrm{m}^{2}$ \\
\hline \multicolumn{5}{|c|}{ FORCE and PRESSURE or STRESS } \\
\hline $\mathrm{lbf}$ & poundforce & 4.45 & newtons & $\mathrm{N}$ \\
\hline Ibf/in ${ }^{2}$ & poundforce per square inch & 6.89 & kilopascals & $\mathrm{kPa}$ \\
\hline \multicolumn{5}{|c|}{ APPROXIMATE CONVERSIONS FROM SI UNITS } \\
\hline Symbol & When You Know & Multiply By & To Find & Symbol \\
\hline \multicolumn{5}{|c|}{ LENGTH } \\
\hline $\mathrm{mm}$ & millimeters & 0.039 & inches & in \\
\hline $\mathrm{m}$ & meters & 3.28 & feet & $\mathrm{ft}$ \\
\hline $\mathrm{m}$ & meters & 1.09 & yards & yd \\
\hline \multirow{2}{*}{\multicolumn{5}{|c|}{ AREA }} \\
\hline & & & & \\
\hline $\mathrm{mm}^{2}$ & square millimeters & 0.0016 & square inches & $\mathrm{in}^{2}$ \\
\hline $\mathrm{m}^{2}$ & square meters & 10.764 & square feet & $\mathrm{ft}^{2}$ \\
\hline $\mathrm{m}^{2}$ & square meters & 1.195 & square yards & $\mathrm{yd}^{2}$ \\
\hline ha, & hectares & 2.47 & acres & ac \\
\hline $\mathrm{km}^{2}$ & square kilometers & 0.386 & square miles & $\mathrm{mi}^{2}$ \\
\hline \multicolumn{5}{|c|}{ VOLUME } \\
\hline $\mathrm{mL}$ & milliliters & 0.034 & fluid ounces & $\mathrm{fl} \mathrm{oz}$ \\
\hline $\mathrm{L}_{3}$ & liters & 0.264 & gallons & gal \\
\hline $\mathrm{m}^{3}$ & cubic meters & 35.314 & cubic feet & $\mathrm{ft}^{3}$ \\
\hline $\mathrm{m}^{3}$ & cubic meters & 1.307 & cubic yards & $\mathrm{yd}^{3}$ \\
\hline \multicolumn{5}{|c|}{ MASS } \\
\hline g & grams & 0.035 & ounces & \\
\hline $\mathrm{kg}$ & kilograms & 2.202 & pounds & Ib \\
\hline $\mathrm{Mg}$ (or "t") & megagrams (or "metric ton") & 1.103 & short tons (2000 lb) & $\mathrm{T}$ \\
\hline \multicolumn{5}{|c|}{ TEMPERATURE (exact degrees) } \\
\hline${ }^{\circ} \mathrm{C}$ & Celsius & $1.8 \mathrm{C}+3$ & Fahrenheit & ${ }^{\circ} \mathrm{F}$ \\
\hline \multicolumn{5}{|c|}{ ILLUMINATION } \\
\hline & & 0.0929 & foot-candles & fc \\
\hline $\mathrm{cd} / \mathrm{m}^{2}$ & candela $/ \mathrm{m}^{2}$ & 0.2919 & foot-Lamberts & $\mathrm{fl}$ \\
\hline \multicolumn{5}{|c|}{ FORCE and PRESSURE or STRESS } \\
\hline $\mathrm{N}$ & newtons & 0.225 & poundforce & lbf \\
\hline $\mathrm{kPa}$ & kilopascals & 0.145 & poundforce per square inch & $\mathrm{lbf} / \mathrm{in}^{2}$ \\
\hline
\end{tabular}

*SI is the symbol for the International System of Units. Appropriate rounding should be made to comply with Section 4 of ASTM E380. (Revised March 2003) 


\section{CONTENTS}

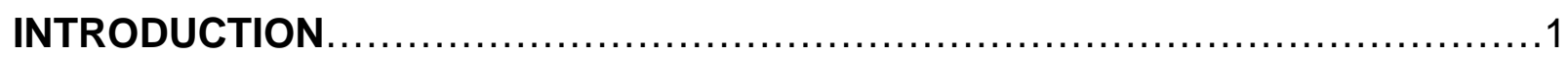

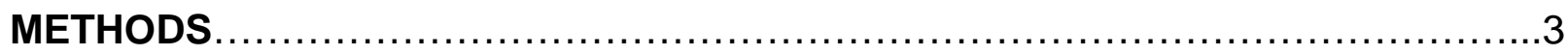

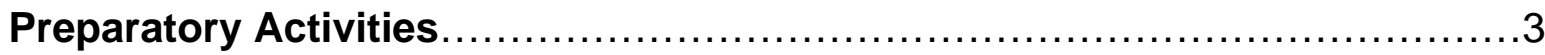

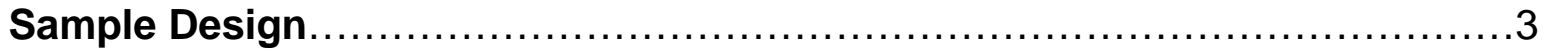

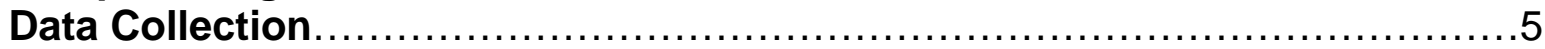

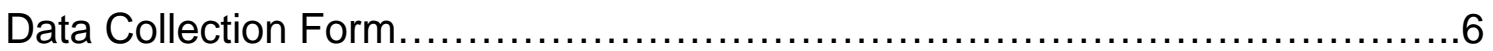

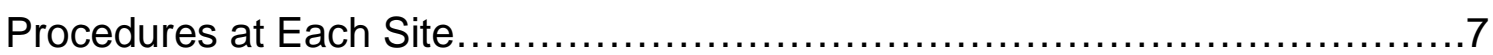

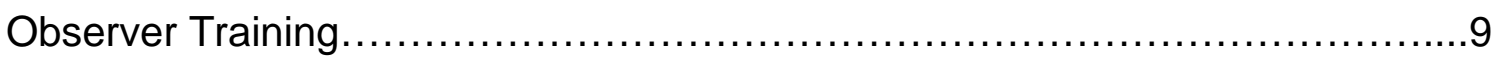

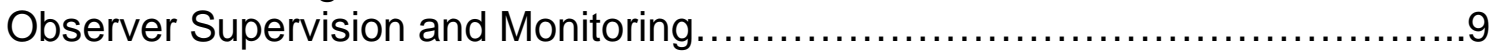

Data Processing and Estimation Procedures............................... 10

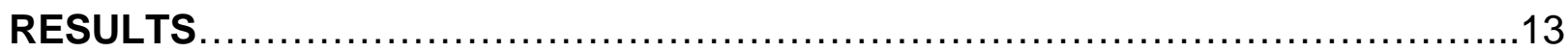

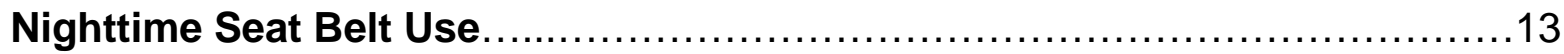

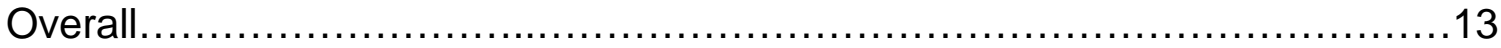

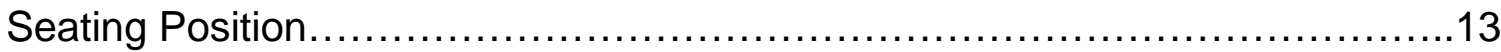

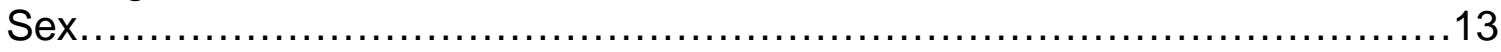

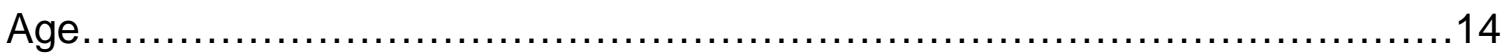

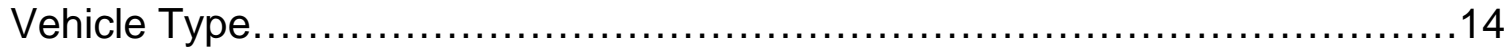

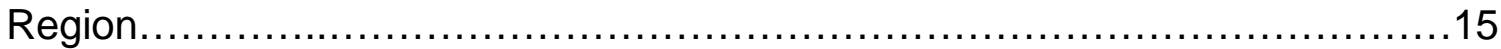

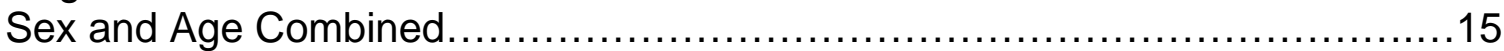

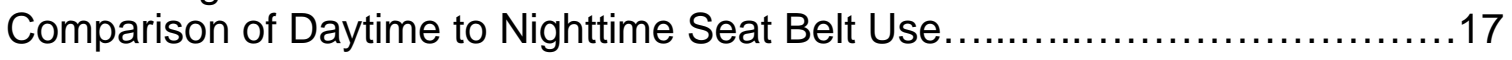

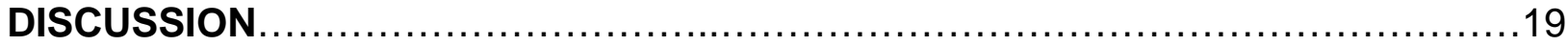

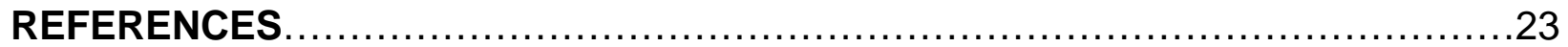




\section{TABLES}

Table 1. Nighttime Shoulder Belt Use, Confidence Interval, and Unweighted N by

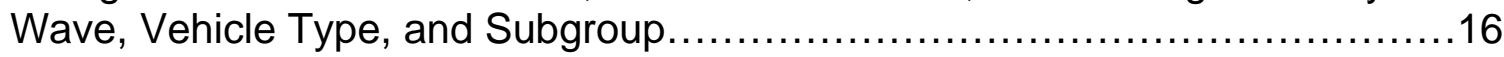

Table 2. Nighttime Shoulder Belt Use and Unweighted $\mathrm{N}$ by Age and Sex.............17

Table 3. Overall Daytime and Nighttime Seat Belt Use Within Each Wave (Percent Use, Confidence Interval, Unweighted N) ..................................18 


\section{ACKNOWLEDGEMENTS}

We express our thanks to several individuals who were essential to the completion of this project. Robert Brown, Ron Fisher, and Robert McMurray conducted field observations. Judy Settles and Mary Chico coordinated administrative procedures for the field observers. The Center for the Advancement of Transportation Safety (CATS) at Purdue University conducted the daytime seat belt surveys in Indiana. Jennifer Howells of CATS assisted in coordinating our survey with theirs. Special thanks to the National Highway Traffic Safety Administration, Indiana Criminal Justice Institute, Indiana State Police, Indiana Sheriff's Association, and Indiana Association of Chiefs of Police for their support.

Jonathon M. Vivoda

David W. Eby

Renée M. St. Louis

Lidia P. Kostyniuk

September 2006 


\section{INTRODUCTION}

The seat belt is the single most effective system for reducing the severity of injuries during a motor vehicle crash. Seat belts are only effective, however, if they are used consistently. The United States has made great strides in increasing use of seat belts, with nationwide belt use now exceeding 80 percent, according to the National Highway Traffic Safety Administration's National Occupant Protection Use Survey (NOPUS) (Glassbrenner, 2005). The NOPUS, however, as well as nearly all other direct observation studies of seat belt use, is conducted during daylight hours. Recent research suggests that nighttime seat belt use may be lower than use rates during the day.

Analyses of Fatality Analysis Reporting System (FARS, 2005) data show that seat belt use among fatally injured front-seat passengers is less than 35 percent between the hours of 10 p.m. and 5 a.m., whereas belt use among fatality-injured passengers between 8 a.m. and 5 p.m. is about 20 percentage points higher. A recent direct observation study of nighttime versus daytime belt use in Connecticut (using night vision technology), found that belt use during the day was 83.0 percent while belt use at night was significantly lower at 76.6 percent use (Chaudhary, Geary, Preusser, \& Cosgrove, 2005). This study also measured daytime and nighttime belt use before and after Connecticut's May 2004 seat belt mobilization campaign. The study found that belt use increased during the daytime and nighttime, but the nighttime belt use increased by a greater number of percentage points. Thus, this study suggested that the mobilization campaign was effective during both the daytime and nighttime, but nighttime belt use was still less frequent than during the daytime.

Another study, reported by Chaudhary, Alonge, and Preusser (2005), addressed the question of whether or not nighttime seat belt enforcement increased use of belts during night hours. The study focused on Reading, Pennsylvania, as the experimental (treatment) location and Bethlehem, Pennsylvania, as the control (non-treatment, comparison) location. The Reading Police Department conducted one month of nighttime seat belt enforcement activity that included checkpoints, roving patrols, and "mini-cades." The officers used night vision equipment to spot unbelted vehicle occupants. Pre- and post-intervention measures of belt use were obtained through 
direct observations conducted at a small sample of sites in both cities. The results showed that Reading belt use increased significantly both during the day and night after the campaign, but nighttime belt use was lower than daytime belt use in both periods. In Bethlehem, daytime belt use actually decreased between the pre- and post- periods while no change was found for nighttime belt use between periods. In both periods, nighttime belt use lagged behind the daytime rates. Collectively, these studies show that belt use is lower at night than during the day and that well-publicized enforcement campaigns either during daytime or nighttime can increase use of belts during the day and at night.

All these studies, however, were conducted exclusively in the Northeastern United States, and did not include a full statewide pre/post survey comparison. There are two main objectives for the current study. The first objective is to measure seat belt use at night surrounding the May 2006 national seat belt mobilization campaign to determine if there is a differential change in daytime versus nighttime seat belt use surrounding the mobilization activities. These comparisons will be made using two full statewide nighttime survey waves conducted by UMTRI in Indiana. In addition, a separate state-funded study consisting of two full daytime survey waves is also being conducted by the Center for the Advancement of Transportation Safety (CATS) at Purdue University. CATS will allow UMTRI access to these data for daytime to nighttime comparisons. Both studies will include a pre-mobilization survey wave timed to occur before any mobilization activities begin, and a post-mobilization wave beginning immediately following the end of enforcement and media activities. A secondary objective of this study is to determine if the pattern of higher belt use during the day found in the previously described studies is also found outside the Northeast region of the United States. Overall, this study will also allow for a better understanding of nighttime seat belt use trends in general. 


\section{METHODS}

\section{Preparatory Activities}

Prior to designing a sample and collecting seat belt data, several preparatory activities were conducted as described in the Competitive Task Order. Information was gathered about states that met certain criteria in order to determine the best state in which to conduct the survey. The first criterion for selecting a state was the region of the country. Since one of the goals of the current study was to determine if the pattern of lower nighttime belt use observed in previous research is also found outside the Northeast region of the United States, States in that area were eliminated. To allow for effective programmatic outreach, NHTSA divides the United States into 10 regions. Only States included in the following NHTSA regions were eligible for inclusion: Central, Great Lakes, Northwest, Rocky Mountain, South Central, and Western. A total of 29 states are included within these regions. Since the Competitive Task Order stated that procedures for collecting nighttime belt use (sampling, site locations, weighting, etc.) must match the daytime procedures already being used in the state, reports of daytime direct observation of seat belt use surveys were obtained from each state and evaluated by research staff. To be eligible for inclusion, the state must have a maximum of approximately 110 observation sites; therefore states with more than 130 were eliminated. This step reduced the number of eligible states to 7 . Since nighttime belt use observations had already been conducted in New Mexico in 2005, this state was also eliminated, leaving the following 6 options: Arizona, Idaho, Indiana, Iowa, Montana, and Nevada. These states were then rank-ordered by preference based upon several methodological and practical differences in how the daytime studies are conducted (e.g., actual number of sites, data collection at controlled intersections, and observation of motorists' demographic characteristics). Based upon these preferences, Indiana was chosen as the best option for conduct of the nighttime seat belt use survey.

\section{Sample Design}

Since one of the goals of this study was to compare daytime seat belt use to nighttime belt use, it was important to develop a nighttime survey that would best match the existing daytime survey in Indiana. The daytime survey is a statewide probabilitybased survey that meets all the NHTSA requirements under section 157. Section 157 was a grant program, now expired, that rewarded States' performance in raising seat 
belt use based on results of observation surveys that met specific criteria set by the Federal government.

To begin development of the nighttime survey, site locations for all 113 daytime sites used in Indiana's statewide survey were obtained from CATS (Indiana's contractor). The data collection and analysis procedures were also obtained from CATS, to ensure the best possible comparison of daytime to nighttime belt use. While designing the schedule for the nighttime survey, every attempt was made to ensure that data from a specific site was collected the same night as the daytime data. However, since all data for the daytime survey in Indiana are collected in seven days using 12 observers, exact matching was not possible. The night-vision equipment necessary for the conduct of this study is very expensive, and the budget only allowed for two sets to be purchased. Therefore the nighttime data collection period was expanded to 13 nights (using a 14-night data collection period was not possible because of the Easter holiday and the scheduled beginning of media activities following the first survey wave). The 13-night data collection period allowed for data to be collected at all 113 sites with only two pairs of observers.

The nighttime schedule was created by first obtaining the daytime schedules and list of sites from CATS. All sites were then mapped and clustered together in such a way that one cluster represented one night of work for one observer pair. Clusters were created by grouping sites that were geographically near one another, and were scheduled for daytime data collection on the same day of week. During this process, 21 clusters were created for nighttime data collection. The minimum number of sites per cluster was three, with a maximum of six. These clusters were then divided between the two observer pairs so that drive time between clusters was minimized as much as possible, but so data collection at each cluster would occur on the "proper" day of week (i.e., the same day of week that daytime observations were conducted for that site). The schedule was designed so that the first week of nighttime data collection coincided with the daytime survey, with a second week of nighttime data collection following that.

Once the clustering procedure was completed, data collection times were assigned to all sites. To begin this process, the shortest route between all of the sites in 
a given cluster was decided (essentially a loop), and each site was numbered. A random number between 1 and the number of sites in the cluster was selected to determine the site where the first observations would take place. Next, the total time required to complete the cluster was determined by estimating the data collection and set-up time at each site, driving time between sites, and break time. A random start time for the first site of the cluster was then determined given the hours of darkness, and the total time required per cluster. Hours of darkness were determined using the time between the end of twilight in the evening to the beginning of twilight in the morning for Indianapolis, Indiana. Twilight times for the month of June were used so that the same schedule could be used during both survey waves. The hours of darkness used in the current study were between 9:30 p.m. and 5:45 a.m. Start and end times for each site were then adjusted based upon the estimated driving and break times throughout the night in each cluster.

Whenever possible (61 of 113 sites), direct day-to-night matching of sites was achieved (i.e., data was collected from a specific site the same night as when the daytime data collection occurred). For the sites where it was not possible to collect data the same night, the same day of week was matched from the first week (daytime collection) to the second week (nighttime collection) whenever possible. This was accomplished for all sites in the survey except 13 . Due to the wide geographic distribution of sites, the limited number of hours of darkness, and the aforementioned holiday and mobilization activities, data from these sites were collected on days of the week when scheduling was logistically possible.

\section{Data Collection}

Trained field staff observed shoulder belt use, sex, age, seating position, vehicle type, and vehicle purpose (commercial or noncommercial) of drivers and front-right passengers during nighttime hours only. Motorists traveling in passenger cars, sportutility vehicles, large vans, minivans, pickup trucks, and box trucks were included in the data collection. Data collection for the first wave (pre-mobilization) took place April 1730, 2006; data collection for the second wave (post-mobilization) occurred June 5-18, 2006. 


\section{Data Collection Form}

Data were collected during the survey using personal digital assistants (PDAs). For a more detailed description of the PDA data collection process, see Vivoda and Eby (2006). An electronic form containing site description categories as well as observation categories was developed for data collection. For each site surveyed, one copy of the electronic data collection form was created in advance. The site description portion of the form allowed observers to provide descriptive information including the site location, lanes of traffic observed, site type (freeway exit and/or entrance ramp, intersection, or road segment), site choice (primary or alternate), traffic control device (traffic light, stop sign, other, or none), observer number, date, day of week, weather, whether or not a median was present, speed limit, time of night, an estimate of the percentage of vehicles observed out of those that passed by, and counts of eligible vehicles. A place on the form was provided for observers to electronically sketch the intersection and to identify their standing location. A comments section was also included to identify landmarks that might be helpful in characterizing the site (e.g., school, shopping mall) and to discuss problems or issues relevant to the site or study.

The observation categories of the data collection form were used to record seat belt use, passenger information, and vehicle information. For each vehicle surveyed, shoulder belt use, sex, and age group of the driver and the front-right passenger was recorded along with vehicle type. Children riding in child restraint devices (CRDs) were recorded but not included in any part of the analyses. Occupants observed with their shoulder belts worn under the arm or behind the back were noted but considered belted in the analysis (wave 1: $N=25$; wave $2: \mathrm{N}=32$ ). These occupants were considered belted since the buckle was connected and the intent of the current study was to identify seat belt use, not belt misuse. Based upon NHTSA (1999) guidelines, the observers also collected data from commercial vehicles, and noted this in the electronic form. A commercial vehicle was defined as a vehicle that is used for business purposes and may or may not contain company logos. This classification includes vehicles marked with commercial lettering or logos, or vehicles with ladders or other tools on them. Commercial vehicles were later excluded from the analyses to exactly match the analysis procedures used for the daytime survey waves. 


\section{Procedures at Each Site}

All sites in the sample were visited by two-person observer teams for a period of 55 minutes. To allow for the most consistent data collection possible, one person in each data collection team (the permanent UMTRI staff member) conducted observations, while the other (temporary staff member) entered data into the PDA. This designation remained constant throughout the entire study. However, both observers were trained for each task in case a change was necessary.

Observers arrived at their assigned data collection site approximately 10 minutes prior to the scheduled start time for the site. Upon arriving at a site, observers determined whether observations were possible. If observations were not possible (e.g., due to construction), observers were instructed to go to an alternate site that had been provided to them. ${ }^{1}$ Otherwise, observers parked in an unobtrusive location nearby and emptied the supplies from the vehicle. One observer then filled out the site descriptors in the electronic form, while the other set up the night vision and safety equipment. During all data collection, observers wore Class-III reflective safety vests and set up a "shoulder work ahead" sign approximately 50 feet from the observers' intended standing location to warn motorists of their presence. Two highly visible traffic cones were also placed on the shoulder of the roadway between the vehicular traffic flow and the observers' location. The items were placed so that they warned drivers that people were standing on the shoulder of the roadway, but did not affect normal traffic flow in any way. Once the equipment was in place, one observer donned the night vision goggle and readied the infrared (IR) spotlight. The observers then moved to their observation position.

At each site, observers conducted a 5-minute count of all eligible vehicles in the designated observation lanes before beginning seat belt observations. Since the traffic volumes at many sites did not allow for every passing vehicle to be observed, these counts were used during the weighting process to account for these vehicles. These counts were also used during weighting to adjust the data appropriately for sites with differing volumes of traffic within a given stratum. Observations began immediately

\footnotetext{
${ }^{1}$ It never became necessary to conduct observations at any alternate sites during either wave of data collection.
} 
after completion of the count and continued for 45 minutes. During the observation period, observers recorded data for as many eligible vehicles as they could observe. The observer conducting the observations held the IR spotlight, aimed it into the passing vehicles (to brighten the occupants), and relayed the belt use and other information to the second observer. ${ }^{2}$ The second observer entered the data into the PDA, and made sure both observers remained safe from passing vehicles and pedestrians. At the end of the observation period, a second 5-minute vehicle count was conducted to be applied during the weighting process. Nearly all other procedures used during data collection at each site matched those used during the daytime surveys in Indiana (i.e., length of time per site, traffic counts, etc.). The only exception to this was the standing location used during the daytime surveys. In some cases, the daytime observers collected data from many lanes of moving traffic, or for traffic both entering and exiting the freeway. In some cases, this was not possible using the night vision equipment and adjustments were made to allow for accurate nighttime data collection.

When the 55-minute duration at each site ended, the observers loaded the equipment into the vehicle, traveled to the next site on the schedule (or the hotel at the end of the night), recharged the IR spotlights during the drive, and repeated the process. At the end of each night of data collection, observers e-mailed data to the project supervisor directly from the PDAs.

When observers were questioned about their presence by a passerby, they informed the person that they were conducting a nighttime traffic survey. If the person persisted, they told the person that the purpose of the survey was to examine nighttime seat belt use, was being conducted for UMTRI and NHTSA, and gave the person the project supervisor's business card. When the observers were questioned by police, they told the officer about the study and showed them the letters of support from UMTRI, the Indiana State Police, the Indiana Sheriff's Association, and the Indiana Association of Chiefs of Police. Observers were never asked to leave a site location by the police during either survey wave.

\footnotetext{
${ }^{2}$ The infrared spotlight does not cast a visible beam. The "brightening" of the occupants described here is only visible when viewed through night vision goggles.
} 


\section{Observer Training}

Prior to data collection, each field observer received a training manual containing detailed information about data collection procedures, PDA use, use of night vision equipment, and administrative policies and procedures. A site schedule identifying the location, date, and time for each site was included in the manual. Each observer team was also provided with an atlas of Indiana, all necessary field supplies, and detailed directions to each scheduled site.

Observers participated in four days of intensive training, including both classroom review of data collection procedures and practice field observations at several sites chosen to represent the types of sites and situations that would be encountered in the field. Training at practice sites focused on PDA use, use of the night vision equipment, completing the electronic form, determining where to stand and which lanes of traffic to observe, conducting the vehicle count, and recording seat belt use and the other demographic and environmental variables. Prior to the second survey wave, one of the temporary observers was replaced. Since the temporary observers in each team did not actually assess seat belt use, but rather entered data into the PDA as it was relayed to them by their partner, this replacement did not have any affect on data collection during the study. Prior to the second survey wave, the new observer underwent a similar training process to that described above.

\section{Observer Supervision and Monitoring}

Since each observer team was comprised of a temporary employee and a permanent employee from UMTRI, any questions or decisions that arose in the field were made by the permanent UMTRI staff member. Following those decisions, the project director was informed as soon as possible. Contact between the field supervisor and field staff was also maintained on a regular basis through telephone calls to report progress and discuss problems encountered in the field, e-mails to the field supervisor from each observer's PDA, and text messages from the field supervisor to the observers' PDAs to alert them to any important information. Field staff were instructed to call the field supervisor's cellular phone if problems arose during the study. 
Incoming data files were examined by the field supervisor as the study progressed, and problems (e.g., missing data, discrepancies between the data collection form and site listing or schedule) were noted and discussed with field staff. Comments in the site description portion of the data collection form that might affect future survey waves (e.g., traffic flow patterns, traffic control devices, site access) were noted.

\section{Data Processing and Estimation Procedures}

Data collected at the 113 Indiana sites during the pre- and post-mobilization periods were analyzed using methods provided by CATS. These methods did not calculate a variance associated with the belt use rates. However, the variances were needed for the determination of 95-percent confidence intervals. All available documentation of the Indiana daytime seat belt survey from 1994 to the present was reviewed, and a method was developed for the calculation of variance. This method took into account Indiana's sampling design and stratification (16 road categories, 8 in rural counties and 8 in urban counties).

The sampling design of the Indiana survey consisted of 16 strata, where each stratum is a road class in either an urban or rural environment, defined in Bridge, Drake, Howells, Thomaz, and Zahnke (2005). This design involved selection of sites using a proportional random sample (Bridge et al., 2005). Vehicles and vehicle occupants were observed as described in the Procedures at Each Site section. Because every vehicle passing through the site could not be observed, traffic counts were conducted at each site, and the observations at each site were weighted by traffic volume.

In each stratum $\mathrm{i}, \mathrm{n}_{\mathrm{i}}$ sites were sampled. In each site $\mathrm{j}$ of stratum $\mathrm{i}, \mathrm{y}_{\mathrm{ij}}$ vehicle occupants were observed, of which $x_{i j}$ were restrained. The hourly traffic volume at each site $\mathrm{j}$ was $\mathrm{g}_{\mathrm{ij}}$.

The restraint use rate at site $j$ of stratum $i$ is:

$$
R_{i j}=\frac{X_{i j}}{y_{i j}}
$$


The restraint use in stratum $i$ is:

$$
R_{i}=\sum_{j=1}^{n_{i}} \frac{g_{i j}}{\sum_{k=1}^{n_{i}} g_{i k}} R_{i j}
$$

The variance of the restraint use in stratum $i$ is:

$$
\operatorname{Var}\left(R_{i}\right)=\frac{n_{i}}{n_{i}-1} \sum_{j=1}^{n_{i}}\left(\frac{g_{i j}}{\sum_{k=1}^{n_{i}} g_{i k}}\right)^{2}\left(R_{i j}-R_{i}\right)^{2}
$$

Weights based on VMT in the stratum relative to the statewide VMT are used to calculate the overall statewide restraint use and variance. Let $W_{i}$ be the proportion of VMT in stratum i relative to the statewide VMT.

$$
W_{i}=\frac{V M T_{i}}{\sum_{k=1}^{16} V M T_{k}}
$$

The statewide restraint use rate is

$$
R=\sum_{i=1}^{16} W_{i} R_{i}
$$

And its variance is:

$$
\operatorname{Var}(R)=\frac{\sum_{i=1}^{16}\left(W_{i}\right)^{2} \operatorname{Var}\left(R_{i}\right)}{\left(\sum_{i=1}^{16} W_{i}\right)^{2}}
$$

The use rate and variance were calculated in this way overall, and for seating position, sex, age group, vehicle type, and region. In some cases, where there were no sites or only one site contributing observations in a given stratum, strata were combined by road class. No sampling weights from site selection were used during the weighting process described here. While using a weighting scheme that included these weights 
would have been preferable to the current method, the original probability of selection for individual sites was not known. Comparisons of seat belt use between the conditions were made by testing hypotheses about the difference of means using the $z$ test. 


\section{RESULTS}

\section{Nighttime Seat Belt Use}

The current section presents the detailed results of seat belt use by the various demographic and environmental characteristics for each nighttime survey wave. It also compares the pre- and post-mobilization nighttime waves to one another, to assess any changes over time in nighttime belt use due to the mobilization activities. The subsequent section compares the overall results of the pre- and post-mobilization nighttime surveys to their respective daytime survey waves to assess any differences between daytime and nighttime belt use.

\section{Overall}

The overall nighttime seat belt use results are presented in Table 1. The nighttime statewide belt use rates for Indiana were $79.0 \pm 1.9$ and $74.0 \pm 2.2$ percent, respectively for waves 1 and 2. As described in the methods section, $z$-tests were preformed to compare means across survey waves. The results of these analyses allowed for rejection of the null hypothesis at the $p<0.001$ level. In other words, overall nighttime seat belt use decreased at a statistically significant level across the mobilization period.

\section{Seating Position}

Table 1 also shows seat belt use rates by vehicle seating position. The z-tests performed on the belt use rates within each seating position across the survey waves revealed that belt use significantly decreased for drivers $(p<0.001)$, but not for passengers. During wave 1 , belt use was statistically significantly higher for passengers than drivers $(p<0.05)$, with no significant difference observed during wave 2 .

Sex

Nighttime seat belt use by sex and survey wave is also shown in Table 1. As is typically found in seat belt use research, belt use for males was significantly lower than that for females in both survey waves. The $z$-tests that were performed to test these means found the difference to be statistically significant at the $p<0.001$ level for each wave. Statistically significant decreases were also observed within each sex across the survey waves ( $p<0.05$ : males; $p<0.01$ : females). 
Age

Belt use rates by age group are presented in Table 1. Age categories used during the surveys are similar to those typically used in seat belt research and were chosen to represent motorists in specific categories. The 0-to-3-year-olds are those required to be seated in child restraint devices (CRD), 4-to-15-year-olds are children typically not yet old enough to drive, 16-to-29-yearolds are considered "young" motorists of driving age, 30-to-59-year-olds are typical adults of driving age, and those 60 and older are considered older drivers. Due to the fact that children seated in CRDs were not included in any part of the analyses, and the generally low numbers of 0-to-3-yearolds observed during the study, this group was eliminated from the analyses. In addition, since a very small number of 4-to-15-year-olds were observed, belt use results from this group should be interpreted with caution. Observed seat belt use for those in the 16-to-29 age group was statistically the same as that for the 30-to-59 age group in both survey waves. This is in contrast to daytime seat belt use research where lower belt use is typically found for 16-to-29-year-olds. Belt use was highest for those age 60 or older in both survey waves, but the difference compared to younger age groups was only statistically significant for wave $1(p<0.001)$.

The analysis of belt use across waves found a statistically significant decrease in use within each age group ( $p<0.05$ : 16-to-29 and 60-and-older groups; $p<0.01$ : 30-to59-year-olds). The most notable decrease (of more than 11 percentage points) was observed among vehicle occupants over 60. Due to low numbers and high variance, the apparent increase in seat belt use observed in the 4-to-15-year-old age group across the survey waves was not statistically significant.

\section{Vehicle Type}

Nighttime seat belt use rates by vehicle type are also shown in Table 1 . When comparing the belt use rates within each vehicle type across the survey waves, statistically significant decreases in seat belt use were observed for pickup truck and SUV occupants $(p<0.05)$.

As is typically found in seat belt research, motorists traveling in pickup trucks had the lowest observed seat belt use rates of any vehicle type during both survey waves. 
These rates were significantly lower $(p<0.001)$ than the rates observed for occupants of cars, minivans, and SUVs. Belt use for those in pickup trucks was also significantly lower than for large-van occupants during wave $2(p<0.05)$, but not during wave 1 . These results are also not surprising since the seat belt use law for Indiana exempts motorists traveling in pickup trucks. The z-tests performed on the belt use rates for motorists traveling in large vans, revealed that these occupants displayed significantly lower belt use than those traveling in cars and minivans during both survey waves $(p<0.05)$. During wave 1 , this rate was also statistically lower than the observed belt use of SUV occupants $(p<0.05)$. When rates for occupants of cars, minivans, and SUVs were compared with one another, the only significant difference was observed during wave 2 between those in cars and SUVs $(p<0.05)$.

Region

Table 1 also presents the nighttime seat belt use results by region (North, Central, and South). The z-tests performed on these data revealed that motorists traveling in the central region during the pre-mobilization wave used seat belts more often than their counterparts in the Northern and Southern regions (Central > North: $p<0.01$; Central > South: $p<0.001$ ). During the post-mobilization wave, belt use was the same across the regions. When comparing across waves, belt use remained statistically unchanged within the Northern region, while belt use for both the Central and Southern regions decreased during the study period $(p<0.001$ : Central; $p<0.05$ : South).

Sex and Age Combined

Table 2 presents the results of seat belt analyses conducted by age and sex combined. Since the Ns were very small when the 0-to-3 and 4-to-15-year-old age groups were divided by sex, those results were excluded from the analyses. During both waves, the seat belt use rates for females of all age groups were significantly higher than those for their male counterparts ( $p<0.001$ : 16-to-29, 30-to-59; $p<0.05$ : 60 and older for both waves). When comparing the different age groups within each sex, belt use for males 60 and older was significantly higher than both of the other two male age groups during wave 1 ( $p<0.001)$. During the post-mobilization wave, belt use was statistically lower for males 16 to 29 ( $p<0.001$ : 16-to-29 < 30-to-59; $p<0.01$ : 16-to-29< 
60 and older). For females, those 60 and older were observed with significantly higher belt use than the other two female age groups during wave $1(p<0.001)$, with no significant differences noted during wave 2 . When comparing within each age and sex category across the survey waves, significant decreases were observed among 16-to$29(p<0.01)$ and 60 -and-older $(p<0.05)$ males, as well as 30 -to-59-year-old females $(p<0.05)$.

\begin{tabular}{|c|c|c|c|c|}
\hline & Wave 1: Pre- & zation & Wave 2: Post & ization \\
\hline & $\begin{array}{l}\text { Percent } \\
\text { Use } \pm \mathrm{Cl}\end{array}$ & $\mathrm{N}$ & $\begin{array}{c}\text { Percent } \\
\text { Use } \pm \mathrm{Cl}\end{array}$ & $\mathrm{N}$ \\
\hline Overall & $79.0 \pm 1.9$ & 3,896 & $74.0 \pm 2.2$ & 5,003 \\
\hline $\begin{array}{l}\text { Seating Position } \\
\text { Driver } \\
\text { Passenger }\end{array}$ & $\begin{array}{l}78.6 \pm 2.0 \\
82.0 \pm 2.9\end{array}$ & $\begin{array}{r}3,139 \\
757\end{array}$ & $\begin{array}{l}73.4 \pm 2.3 \\
76.7 \pm 5.0\end{array}$ & $\begin{array}{l}3,937 \\
1,066\end{array}$ \\
\hline $\begin{array}{l}\frac{\text { Sex }}{\text { Male }} \\
\text { Female }\end{array}$ & $\begin{array}{l}73.1 \pm 3.1 \\
88.2 \pm 2.0\end{array}$ & $\begin{array}{l}2,345 \\
1,538\end{array}$ & $\begin{array}{l}68.2 \pm 2.6 \\
83.2 \pm 2.7\end{array}$ & $\begin{array}{l}2,951 \\
2,047\end{array}$ \\
\hline $\begin{array}{l}\frac{\text { Age }}{4}-15 \\
16-29 \\
30-59 \\
60-U p\end{array}$ & $\begin{array}{c}74.0 \pm 13.9 \\
77.7 \pm 3.8 \\
79.6 \pm 2.1 \\
89.9 \pm 6.1\end{array}$ & $\begin{array}{r}35 \\
1,533 \\
2,178 \\
149\end{array}$ & $\begin{array}{c}89.7 \pm 14.9 \\
71.5 \pm 3.4 \\
74.9 \pm 2.9 \\
78.7 \pm 9.1\end{array}$ & $\begin{array}{r}61 \\
1,887 \\
2,847 \\
206\end{array}$ \\
\hline $\begin{array}{l}\text { Vehicle Type } \\
\text { Car } \\
\text { SUV } \\
\text { Minivan } \\
\text { Large Van } \\
\text { Pickup }\end{array}$ & $\begin{array}{c}83.1 \pm 2.4 \\
83.0 \pm 3.2 \\
82.9 \pm 4.4 \\
67.8 \pm 16.9 \\
61.7 \pm 6.2\end{array}$ & $\begin{array}{r}2,303 \\
619 \\
352 \\
50 \\
572\end{array}$ & $\begin{array}{c}81.5 \pm 2.8 \\
76.5 \pm 5.1 \\
84.8 \pm 5.3 \\
66.8 \pm 13.5 \\
52.2 \pm 6.0\end{array}$ & $\begin{array}{r}2,917 \\
791 \\
464 \\
66 \\
765\end{array}$ \\
\hline $\begin{array}{l}\text { Region } \\
\text { North } \\
\text { Central } \\
\text { South }\end{array}$ & $\begin{array}{l}78.8 \pm 2.4 \\
83.1 \pm 2.1 \\
76.4 \pm 2.5\end{array}$ & $\begin{array}{r}2,027 \\
1,177 \\
692\end{array}$ & $\begin{array}{l}75.5 \pm 2.9 \\
74.9 \pm 3.2 \\
72.2 \pm 2.9\end{array}$ & $\begin{array}{l}2,556 \\
1,427 \\
1,020\end{array}$ \\
\hline
\end{tabular}


Table 2. Nighttime Shoulder Belt Use and Unweighted N by Age and Sex

\begin{tabular}{|c|c|c|c|c|}
\hline \multicolumn{5}{|c|}{ Wave 1: Pre-Mobilization } \\
\hline \multirow{2}{*}{ Age Group } & \multicolumn{2}{|l|}{ Male } & \multicolumn{2}{|c|}{ Female } \\
\hline & Percent Use $\pm \mathrm{Cl}$ & $\mathbf{N}$ & Percent Use $\pm \mathrm{Cl}$ & $\mathbf{N}$ \\
\hline $\begin{array}{l}16-29 \\
30-59 \\
60-U p\end{array}$ & $\begin{array}{l}71.7 \pm 6.0 \\
73.1 \pm 3.1 \\
87.4 \pm 6.8\end{array}$ & $\begin{array}{c}932 \\
1,306 \\
84\end{array}$ & $\begin{array}{l}86.9 \pm 3.6 \\
88.7 \pm 2.3 \\
96.4 \pm 4.2\end{array}$ & $\begin{array}{c}597 \\
863 \\
65\end{array}$ \\
\hline \multicolumn{5}{|c|}{ Wave 2: Post-Mobilization } \\
\hline \multirow{2}{*}{ Age Group } & \multicolumn{2}{|l|}{ Male } & \multicolumn{2}{|c|}{ Female } \\
\hline & Percent Use $\pm \mathrm{Cl}$ & $\mathbf{N}$ & Percent Use $\pm \mathrm{Cl}$ & $\mathbf{N}$ \\
\hline $\begin{array}{l}16-29 \\
30-59 \\
60-U p\end{array}$ & $\begin{array}{l}61.0 \pm 3.0 \\
70.4 \pm 3.6 \\
74.2 \pm 9.9\end{array}$ & $\begin{array}{c}1,049 \\
1,748 \\
116\end{array}$ & $\begin{array}{c}83.6 \pm 3.1 \\
83.1 \pm 4.1 \\
87.8 \pm 11.2\end{array}$ & $\begin{array}{c}838 \\
1,097 \\
89\end{array}$ \\
\hline
\end{tabular}

\section{Comparison of Daytime to Nighttime Seat Belt Use}

As described earlier, the nighttime survey waves reported here were designed, conducted, and analyzed by UMTRI. These waves were based upon, and designed to match as closely as possible, the statewide daytime survey regularly conducted in Indiana. The two daytime waves were designed and conducted by Indiana contractors (CATS) using state funds separate from those allotted for this study. Overall daytime rates reported here are based upon data generously provided to UMTRI by CATS to allow for study comparisons. These data were analyzed by UMTRI for comparison purposes using the same procedures used by CATS and as described for the nighttime survey waves.

Overall belt use rates observed during the daytime and nighttime survey waves are presented in Table 3. Belt use observed during the daytime and nighttime premobilization waves was very similar. During the post-mobilization waves, daytime belt use was 10.3 percentage points higher than nighttime use. The two-tailed $z$-tests performed on these data revealed a significant difference at the $p<0.001$ level. Comparison of the two daytime waves to one another also revealed a statistically significant increase in daytime belt use following the mobilization activities $(p<0.001)$. 
Additionally, as mentioned earlier, the overall analysis of the pre- and post-mobilization nighttime survey waves revealed a statistically significant decrease in seat belt use during this time period.

Table 3. Overall Daytime and Nighttime Seat Belt Use Within Each Wave (Percent Use, Confidence Interval, Unweighted N)

\begin{tabular}{||c|c|c|c||c|c|c|c||}
\hline \hline \multicolumn{2}{|c|}{ Daytime Pre } & \multicolumn{2}{c||}{ Nighttime Pre } & \multicolumn{2}{c||}{ Daytime Post } & \multicolumn{2}{c||}{ Nighttime Post } \\
\hline $\begin{array}{c}\text { Percent } \\
\text { Use } \pm \mathrm{Cl}\end{array}$ & $\mathrm{N}$ & $\begin{array}{c}\text { Percent } \\
\text { Use } \pm \mathrm{Cl}\end{array}$ & $\mathrm{N}$ & $\begin{array}{c}\text { Percent } \\
\text { Use } \pm \mathrm{Cl}\end{array}$ & $\mathrm{N}$ & $\begin{array}{c}\text { Percent } \\
\text { Use } \pm \mathrm{Cl}\end{array}$ & $\mathrm{N}$ \\
\hline \hline $79.7 \pm 1.3$ & 19,077 & $79.0 \pm 1.9$ & 3,896 & $84.3 \pm 1.4$ & 19,934 & $74.0 \pm 2.2$ & 5,003 \\
\hline
\end{tabular}




\section{DISCUSSION}

The estimated statewide nighttime seat belt use rate for the pre-mobilization survey wave was $79.0 \pm 1.9$ percent. The rate for the post-mobilization nighttime wave was $74.0 \pm 2.2$ percent. As described earlier, there were two main purposes for this study. The first purpose was to measure seat belt use at night surrounding the May Mobilization 2006 activities. The conduct of these nighttime survey waves was intended to allow for a better understanding of nighttime seat belt use trends in general, and to determine if there was a differential change in daytime versus nighttime seat belt use surrounding the mobilization activities. A secondary purpose of the study was to compare daytime to nighttime seat belt use to see if there was lower seat belt use at night, as has been found by others (Chaudhary et al., 2005).

To determine if there was a differential change over time in daytime versus nighttime seat belt use surrounding the mobilization activities, the overall seat belt use rates observed during the daytime waves were compared to one another, as were the rates from the nighttime waves. These analyses revealed that the mobilization activities were successful at increasing daytime seat belt use in Indiana. Conversely, the overall seat belt use rates observed during the nighttime waves decreased at a statistically significant level across the mobilization period. These results suggest that the mobilization activities conducted in Indiana positively affected daytime belt use, but had no effect on nighttime belt use. There is no obvious reason for the decrease in nighttime belt use observed during this time period.

While Chaudhary et al. (2005) found an increase in nighttime seat belt use observed concurrently with a daytime seat belt mobilization, the results noted in the current study are still not surprising since the mobilization activities were primarily conducted during daytime hours. Possible explanations for these different results include the idea that the daytime enforcement or media activities implemented in the two areas (Connecticut in 2004 and Indiana in 2006) were different in some way that affected the outcome. Another difference between the two studies is that the current study used a full statewide daytime and nighttime survey for the pre-mobilization and post-mobilization waves, instead of the mini-survey pre-, and full-survey post- 
mobilization format used by Chaudhary et al. (2005). The full-survey methodology allows for a better direct comparison of seat belt use rates. These possibilities should be explored with future nighttime seat belt research.

To make direct comparisons of daytime to nighttime belt use, results from two full statewide daytime surveys (conducted by CATS) and two full statewide nighttime surveys (conducted by UMTRI) were used in Indiana. During the pre-mobilization wave, there was no statistically significant difference between daytime and nighttime belt use. However during the post-mobilization wave, a significant difference of 10.3 percentage points was observed. This difference can be jointly attributed to the differential effect of the mobilization activities on daytime and nighttime belt use, as well as the decrease noted across the nighttime waves. The results found during wave 2 are similar to those found by Chaudhary et al. (2005), suggesting that seat belt use is lower at night than during the day. However, the results observed during wave 1 may provide a better comparison, since that survey served as a baseline and occurred before any seat belt promotion activities began in the state.

The current study also conducted several other comparisons of nighttime seat belt use within various demographic and environmental categories. Since direct observation of nighttime belt use is a relatively new undertaking, it is not known if common daytime belt use trends hold true during hours of darkness. Nearly all daytime seat belt research has found that males, those traveling in pickup trucks, vehicle passengers, and young occupants use seat belts less often than other groups (see e.g., Eby, Vivoda, and Spradlin, 2003; Glassbrenner, 2004). However, during the nighttime waves, the typical daytime effects of age and seating position were not observed. During wave 1, belt use was significantly higher for those 60 and older, but there was no difference between those 16 to 29 and 30 to 59. During wave 2, there were no significant differences in belt use between any of the age groups. The lack of a difference observed during the nighttime waves may represent a difference in behavior between daytime and nighttime motorists. It is possible that drivers of all ages perceive less of a threat of receiving a citation during hours of darkness (or perceive that threat to be equal, regardless of age). If that is the case, differences in belt use at night would not be reflected within the different age categories. The analyses by seating position 
found higher belt use for passengers than drivers within both waves, with a statistically significant difference observed during wave 1 . Typically, drivers are observed with higher seat belt use than others in the vehicle. While the current study did not attempt to understand why these potential differences occurred, one possible explanation is that those who travel during hours of darkness may be different from those that travel during the day in some meaningful way that cannot be easily observed. In other words, differences in belt use at night may not reflect a difference in behavior within the same population, but rather may reflect the "normal" behavior of a different population. Future nighttime observational research should continue to explore this finding. 


\section{REFERENCES}

Bridge, C.S., Drake, M.L., Howells, J.M., Thomas, J.E., \& Zahnke, R.C. (2005). Indiana Roadside Observation Survey of Safety Belt Use and Motorcycle Helmet Use. West Lafayette, IN: Center for the Advancement of Transportation Safety, Purdue University

Chaudhary, N.K., Alonge, M., \& Preusser, D.F. (2005). Evaluation of the Reading, PA, nighttime safety belt enforcement campaign: September 2004. Journal of Safety Research, 36, 321-326.

Chaudhary, N.K., Geary, L.L., Preusser, D.F., \& Cosgrove, L.A. (2005). Connecticut's Day and Night Safety Belt Use. DOT-HS-809-954. Washington, DC: National Highway Traffic Safety Administration.

Eby, D.W., Vivoda, J.M., \& Spradlin, H.K. (2003). Direct Observation of Safety Belt Use in Michigan: Fall 2003. Report No. UMTRI-2003-40. Ann Arbor, MI: University of Michigan Transportation Research Institute.

Fatality Analysis Reporting System (2005). 2003 data accessed May 18, 2005. National Highway Traffic Safety Administration URL:

http://wwwfars.nhtsa. dot.gov/finalreport.cfm?title=Crashes\&stateid=0\&year=2003\&ti tle2=Time

Glassbrenner, D. (2004). Safety Belt Use in 2003 - Demographic Characteristics. DOT-HS-809-729. Washington, DC: National Highway Traffic Safety Administration.

Glassbrenner, D. (2005). Safety belt use in 2005 - overall results. Traffic Safety Facts Research Note. DOT-HS-809-932. Washington, DC: National Highway Traffic Safety Administration.

National Highway Traffic Safety Administration. (1999, personal communication). Letter to the executive director of the Michigan Office of Highway Safety Planning outlining Federal regulations regarding inclusion of commercial/noncommercial vehicle occupants. April, 1999.

National Highway Traffic Safety Administration. (2004). Indiana: Marion County Traffic Safety Partnership Nighttime Safety Belt Enforcement Zones. Traffic Safety Digest, 2. [electronic version].

Vivoda, J.M. \& Eby, D.W. (2006). Using personal digital assistants (PDAs) for the collection of safety belt use data in the field. Behavior Research Methods, Instruments, and Computers, 38, 158-164. 